Int. J. Electrochem. Sci., 11 (2016) $8447-8458$

International Journal of

ELECTROCHEMICAL

SCIENCE

www.electrochemsci.org

\title{
Poly(o-toluidine) Modified Platinum Electrode As an Electrocatalyst for Benzyl Alcohol Oxidation in Acid Media
}

\author{
Mohamed EL-Deeb ${ }^{1,2, *}$ and Hamed Alshammari ${ }^{1}$ \\ ${ }^{1}$ Chemistry Department, Faculty of Science, Ha'il University, 81451 Hail, P.O. Box 2440, KSA \\ ${ }^{2}$ Chemistry Department, Faculty of Science, Beni-Suef University, 62514 Beni-Suef, Egypt \\ *E-mail: eldeebm@yahoo.com
}

doi: $10.20964 / 2016.10 .54$

Received: 24 May 2016 / Accepted: 26 July 2016 / Published: 6 September 2016

The heterogeneous electrocatalytic behavior of poly (o-toluidine) modified platinum electrode (Pt/o$\mathrm{CH}_{3}$ ) towards benzyl alcohol oxidation in acid medium is investigated using a cyclic voltammetry technique under different experimental conditions. Electrode modification is carried out by the electrodeposition of poly (o-toluidine) films on platinum surface and the obtained films are characterized using FTIR and UV-visible spectroscopy as well as the mechanism of the electrodeposition process is discussed. Data shows that, the oxidation potential of benzyl alcohol at modifying electrode $\left(\mathrm{Pt} / \mathrm{o}-\mathrm{CH}_{3}\right)$ is shifted to more negative value compared with that at the platinum electrode $(\mathrm{Pt})$ under the same conditions and the anodic current densities of the electrooxidation process enhances with increasing the monomer and alcohol concentrations. The electrocatalytic activity of the modified electrode can be explained as a result of the synergistic effects of the conducting polymer film coated platinum surface. Also, the electrooxidation process at modified electrode is described partially by a diffusion-controlled process

Keywords: Electrooxidation, Electrodeposition, Polymer Modified Electrode, Benzyl Alcohol, Cyclic Voltammetry, spectroscopic characterization.

\section{$\underline{\text { FULL TEXT }}$}

(C) 2016 The Authors. Published by ESG (www.electrochemsci.org). This article is an open access article distributed under the terms and conditions of the Creative Commons Attribution license (http://creativecommons.org/licenses/by/4.0/). 